\title{
Produção e Caracterização de Microesferas de Quitosana Modificadas Quimicamente
}

\author{
Marco A. Torres, Rodrigo S. Vieira, Marisa M. Beppu, Cesar C. Santana \\ Faculdade de Engenharia Química, UNICAMP
}

Resumo: Microesferas de quitosana podem ser empregadas na área de biomaterias, em processos biotecnológicos e como adsorventes. Neste trabalho, foi empregada a técnica de atomização e coagulação para produção dessas microesferas, que permitiu o controle dos parâmetros de operação e por conseqüência a obtenção de microesferas de tamanho e faixas de tamanho específicos. Após a sua obtenção, as microesferas foram modificadas quimicamente com objetivo de estudar as resistências térmica, mecânica e química. Para isso foram empregadas três rotas distintas: a-) reticulação com glutaraldeído; b-) reticulação com epicloridrina e c-) acetilação. As microesferas preparadas apresentaram distribuição de tamanho da ordem de $140 \mu \mathrm{m}$ com desvio padrão de $11,9 \mu \mathrm{m}$. Após as modificações químicas, as microesferas apresentaram temperatura de degradação térmica em torno de $300{ }^{\circ} \mathrm{C}$, aumento da estabilidade química à solução de $\mathrm{HCl}$, e diminuição da resistência mecânica.

Palavras-chave: Quitosana, microesferas, atomização, modificação química.

\section{Production and Characterization of Chemically Modified Chitosan Microspheres}

Abstract: Chitosan microspheres can be used as biomaterial, in biotechnology processes and as adsorbents. This work is concerned with the production of chitosan microspheres using spraying and coagulation processes, which allows us to control the operating parameters and to produce chitosan microspheres of several ranges and sizes. The microspheres were modified chemically in order to study their thermal, mechanical and chemical resistance. The methods used were: 1 ) crosslinking with glutaraldehyde; 2) crosslinking with epichlorohydrin; 3) acetylation. The microspheres obtained presented mean particle size of $140 \mu \mathrm{m}$ and standard deviation of $11.9 \mu \mathrm{m}$. The modified microspheres showed thermal degradation around $300{ }^{\circ} \mathrm{C}$, an increase of chemical stability using $\mathrm{HCl}$ solution and a decrease of mechanical resistance.

Keywords: Chitosan, microspheres, spraying, chemical modification.

\section{Introdução}

A quitosana é um aminopolissacarídeo biodegradável, hidrofílico, não tóxico e biocompatível obtido a partir da desacetilação alcalina da quitina ${ }^{[1-3]}$. Sua estrutura química é formada pelos copolímeros $\beta$-(1 $\rightarrow 4)$ - 2-amino 2-desoxiD-glicose e $\beta$-(1 $\rightarrow 4)$ - 2-acetamida 2-desoxi-D-glicose com a presença de grupos amino e grupos hidroxila primário e secundário. A quitosana vem sendo estudada como biomaterial de potencial aplicação principalmente nas áreas médica e farmacêutica ${ }^{[4-6]}$. Yamaguchi, et al. ${ }^{[7]}$ observaram compósitos de quitosana e suas aplicações na regeneração de nervos. Mi, et al. ${ }^{[8]}$ realizaram estudos sobre a quitosana aplicada na liberação controlada de fármacos. É crescente, também, a importância da quitosana como adsorvente, em processos de recuperação e/ou de purificação de bioprodutos de alto valor agregado, como as proteínas.

Uma vantagem dessa utilização está na disponibilidade da quitosana na natureza através da quitina, podendo ser facilmente encontrada, como subproduto da indústria pesqueira.
Devido à sua natureza policationica, quando a quitosana entra em contato com soluções ácidas é possível a sua moldabilidade nas mais diversas formas como membranas, esferas, gel, microesferas, etc.

Recentemente, alguns artigos têm sido publicados descrevendo a preparação de microesferas de quitosana pelos métodos de secagem por atomização ${ }^{[9]}$ e pelo método de emulsão ${ }^{[10]}$. Neste trabalho, as microesferas de quitosana foram preparadas a partir da técnica de atomização e coagulação. O método utilizado é simples, de fácil aumento de escala e bastante reprodutível.

Uma outra característica importante da quitosana está na possibilidade de modificações estruturais de modo a obter diversas formas de interação química e resistência mecânica. As microesferas obtidas foram então modificadas quimicamente, com objetivo de estudar o grau de desacetilação e as resistências mecânica, química e térmica aumentando as suas possibilidades de aplicação. Foram escolhidas para isso três rotas distintas: a-) reticulação com glutaraldeído, através do bloqueio dos grupos amino presentes na quitosana pelos grupos aldeídos ${ }^{[11,12]}$; b-) reticulação com epicloridrina,

Autor para correspondência: Marco A. Torres, Faculdade de Engenharia Química, UNICAMP, Caixa Postal 6066, CEP: 3083-970, Campinas, SP. E-mail: marco@feq.unicamp.br 


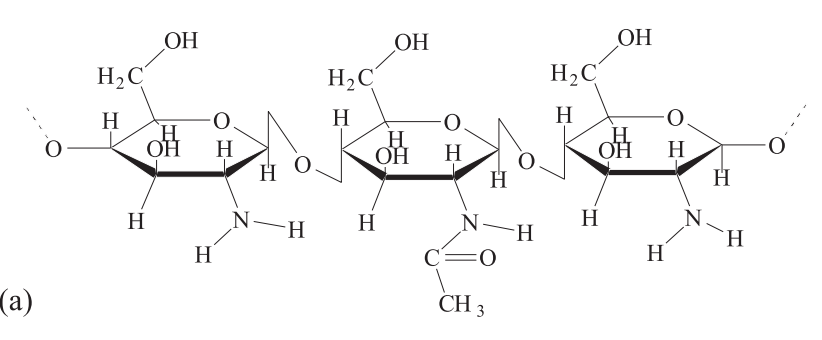

(c)

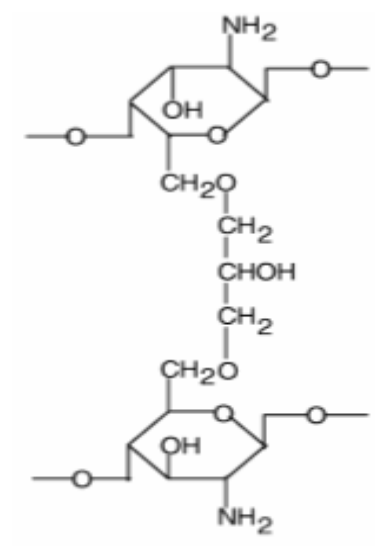

(b)

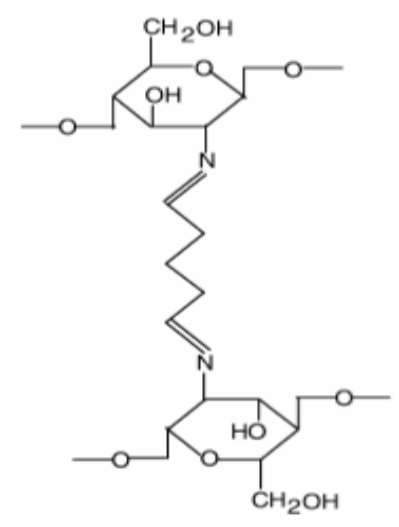

(d)

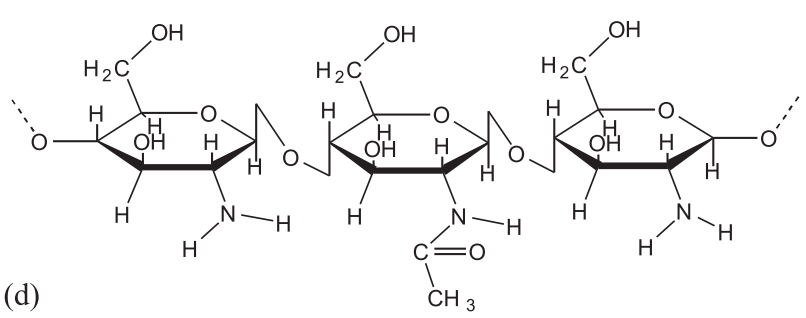

Figura 1. Estrutura molecular dos segmentos da cadeia das amostras, natural (a), reticulada com glutaraldeído (b), reticulada com epicloridrina (c) e acetilada (d).

através do bloqueio preferencial das hidroxilas ${ }^{[13,14]}$ e c-) acetilação, diminuindo o grau de desacetilação da quitosana através da formação de pseudo-quitinas ${ }^{[15]}$. A Figura 1 mostra as possíveis estruturas químicas formadas após o processo de reticulação e acetilação da quitosana.

Após preparação das microesferas de quitosana pelo método de atomização e coagulação e modificação pelas três rotas as microesferas foram caracterizadas e avaliadas comparativamente segundo os métodos de titulação potenciométrica, espectroscopia de reflexão total atenuada no infravermelho, análises térmicas por TGA e DSC, análise mecânica por DMA e análise de resistência química ao ácido $\mathrm{HCl}$.

\section{Experimental}

\section{Estabelecimento de parâmetros do processo}

A esfericidade foi afetada (no nosso caso) pela distância entre o bico de atomização e a solução coagulante. Distâncias maiores permitiram diminuição do impacto entre o borrifo e a solução de $\mathrm{NaOH}$, com obtenção de partículas mais esféricas $^{[16]}$. Esse parâmetro foi então fixado em $30 \mathrm{~cm}$.

Durante a operação do sistema observou-se que o aumento da pressão de nitrogênio em relação à vazão mássica da solução de quitosana diminui o tamanho médio das partículas. O resultado foi oposto quando aumentamos a vazão mássica da solução de quitosana em relação à pressão de nitrogênio. Já o aumento da concentração da solução de quitosana diminui, por sua vez, a capacidade de quebra das gotas (atomização), ou seja, aumenta o tamanho das partículas obtidas. A condição mais uniforme de distribuição do tamanho das microesferas de quitosana foi obtida a partir das seguintes condições: corrida utilizando-se solução de quitosana na concentração de 2,5\% em massa bombeada peristalticamente através da bomba Cole Parmer operando na vazão de $9,0 \mathrm{ml} \cdot \mathrm{min}^{-1}$ e pressão na linha de nitrogênio de 2,5 kgf.cm ${ }^{-2}$ com temperatura constante de $25^{\circ} \mathrm{C}$ e abertura do bico de atomização de $0,5 \mathrm{~mm}$. Foi possível verificar limitações no aumento da pressão de nitrogênio e na vazão da solução de quitosana. Valores acima de 2,5 kgf.cm ${ }^{-2}$ de pressão de nitrogênio causaram refluxo na corrente de entrada da solução de quitosana. Valores acima de $9,0 \mathrm{ml} \cdot \mathrm{min}^{-1}$ de vazão da solução de quitosana diminuíram a eficiência da atomização, esta limitação está relacionada com o tamanho da câmara onde ocorre a atomização. A concentração da solução de quitosana possui grande influência na eficiência do processo, mas foi mantida em $2,5 \%$, pois a sua diminuição afeta a condição de reatividade das microesferas dependendo da sua utilização final. A variação da temperatura da solução de quitosana teve inicialmente pouca influência na vazão da solução, já que para alterar as suas propriedades viscoelásticas é necessário um gradiente de temperatura superior a $20^{\circ} \mathrm{C}^{[17]}$.

\section{Preparação das microesferas de quitosana}

Inicialmente a quitosana foi solubilizada em solução aquosa de ácido acético, contendo 3\% (v/v) de ácido acético em água Milli-Q. Para obtenção das microesferas de quitosana foi utilizado o método de atomização e coagulação. As eta- 


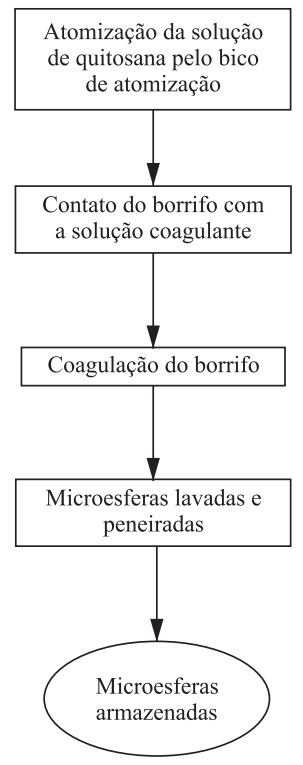

Figura 2. Fluxograma da produção de microesferas.

pas são mostradas na Figura 2. O sistema utilizado para a preparação das microesferas é mostrado na Figura 3. A solução concentrada de quitosana foi bombeada na vazão de 9,0 ml.min ${ }^{-1}$ utilizando uma bomba peristáltica (Cole Parmer) através de uma linha de silicone até o bico de atomização (Spraying System JBC) com abertura de $0,5 \mathrm{~mm}$. A atomização da solução ocorreu a partir do contato com gás nitrogênio sob pressão de 2,5 kgf.cm ${ }^{-2}$ e foi dispersa em direção à solução de hidróxido de sódio $\mathrm{NaOH} 1 \mathrm{~mol} / \mathrm{L}$, permanecendo em contato e repouso com a solução coagulante por 12 horas. As microesferas estabilizadas estruturalmente apresentam um aspecto branco opalescente, devido ao espalhamento de luz através dos seus poros. As microesferas foram então drenadas utilizando-se peneiras de tamanho de malha de $0,035 \mathrm{~mm}$ e $0,150 \mathrm{~mm}$ com o intuito de selecionar o tamanho das microesferas. A fração intermediária foi então lavada com água deionizada e estocada em temperatura de $7{ }^{\circ} \mathrm{C}$.

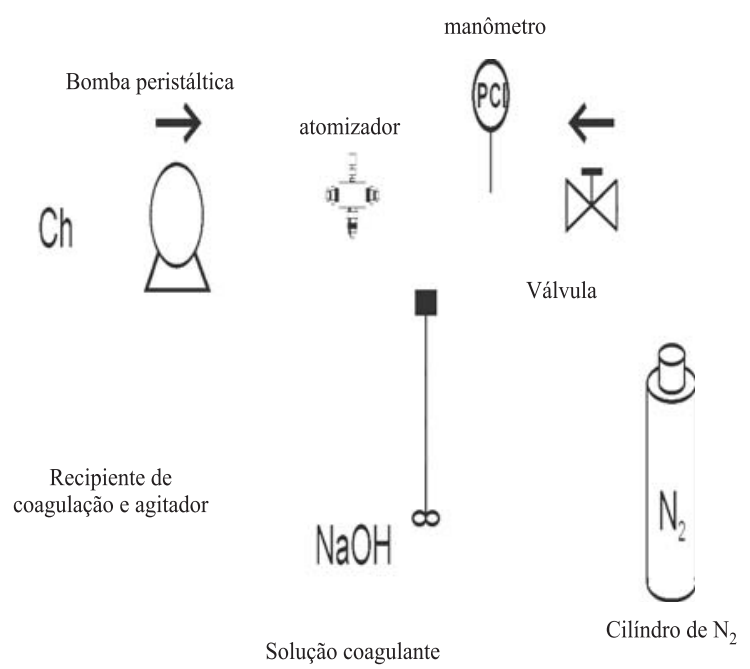

Figura 3. Representação esquemática da produção de microesferas de quitosana.

\section{Modificação química das microesferas}

As microesferas obtidas pela técnica de atomização e coagulação foram modificadas quimicamente com glutaraldeído, epicloridrina e anidrido acético.

$\mathrm{Na}$ primeira rota, as microesferas foram reticuladas em solução aquosa de glutaraldeído $0,75 \%$ em massa ( $5 \mathrm{~g}$ de microesferas úmidas em $50 \mathrm{ml}$ de solução de glutaraldeído), sem agitação, na temperatura ambiente por $2 \mathrm{~h}$. Em seguida, as microesferas foram lavadas com água Milli-Q para remoção do excesso de glutaraldeído.

No processo de reticulação com epicloridrina, $5 \mathrm{~g}$ de microesferas úmidas foram imersas em solução de epicloridrina na concentração de $0,01 \mathrm{~mol} / \mathrm{L}$. A solução utilizada foi preparada com $0,067 \mathrm{~mol} / \mathrm{L}$ de $\mathrm{NaOH}$. A solução com as microesferas foi agitada durante $2 \mathrm{~h}$ na temperatura de $40{ }^{\circ} \mathrm{C}$. Em seguida, as microesferas foram lavadas com água Milli-Q para remoção do excesso de epicloridrina.

$\mathrm{Na}$ terceira rota, as microesferas foram modificadas usando solução de $0,6 \%$ em volume de anidrido acético em solução de metanol, na temperatura ambiente e agitação contínua por 3 min. Em seguida, as microesferas foram lavadas com metanol para remoção do anidrido acético em excesso.

As microesferas de quitosana foram então separadas em: (a) microesferas sem modificação alguma (natural); (b) microesferas reticuladas com glutaraldeído; (c) microesferas reticuladas com epicloridrina e (d) microesferas acetiladas.

\section{Microscopia óptica}

Para avaliação morfológica das microesferas foi utilizado um microscópio óptico Leica DMLM. As microesferas, após liofilização, foram imersas em óleo mineral para facilitar a dispersão e conseqüente visualização. $\mathrm{O}$ aumento utilizado foi de $200 \mathrm{x}$.

\section{Distribuição de tamanho das microesferas}

A distribuição do tamanho das microesferas foi realizada em triplicata e obtida utilizando o equipamento Mastersize $\mathrm{S}$. A técnica consiste no espalhamento da luz (laser, com comprimento de onda de $488 \mathrm{~nm}$ ) pelas partículas da amostra, sendo o tamanho inversamente proporcional ao desvio do ângulo da luz espalhada de acordo com a teoria Mie. Essa teoria permite descrever um objeto tri-dimensional (no nosso caso as microesferas) através de um número, utilizando para isso o modelo de uma esfera equivalente.

\section{Titulação potenciométrica}

A quantidade de grupos amino protonáveis foi determinada para cada amostra através de ensaios de titulação potenciométrica. Nesse método, uma quantidade conhecida de microesferas (sem modificação ou modificadas) é adicionada à uma solução de $\mathrm{HCl}(0,02$ equiv-g/L), permitindo o carregamento dos grupos protonáveis (grupos amino). Em seguida, a solução resultante é titulada com uma solução de $\mathrm{NaOH}(0,01$ equiv-g/L). Com as curvas de titulação e os respectivos pontos de inflexão é possível determinar o percentual de grupos amino, conforme a Equação 1. 


$$
\% \mathrm{NH}_{2}=\frac{M_{\mathrm{NaOH}} *\left(V_{2}-V_{1}\right) * 161}{m} * 100
$$

onde $\mathrm{M}_{\mathrm{NaOH}}$ é a molaridade da solução de $\mathrm{NaOH}(\mathrm{mols} / \mathrm{L})$, $\mathrm{V}_{1}$ e $\mathrm{V}_{2}$ são os volumes de $\mathrm{NaOH}$ usados respectivamente para neutralizar o excesso de $\mathrm{HCl}$ e a amostra de quitosana protonada, 161 é a massa molecular da unidade monomérica da quitosana e $m$ é a massa de amostra utilizada para a titulação em gramas.

\section{Infravermelho(FTIR-ATR)}

Nesse estudo foram realizadas análises utilizando-se a técnica de espectroscopia de infravermelho por transformada de Fourier (FTIR) acoplada a um elemento de reflexão total atenuada (ATR). O espectro foi varrido de 4000 a $400 \mathrm{~cm}^{-1}$ com resolução de $16 \mathrm{~cm}^{-1}$. O equipamento utilizado foi FTIR da Nicolet Protégé, com acessório ATR de cristal de germânio.

\section{Análises térmicas por TGA e DSC}

As análises térmicas foram realizadas para observação do comportamento e da estabilidade térmica de cada amostra. Devido à especificidade das reações físico-químicas que ocorrem numa banda definida de temperatura e velocidade, foi possível ter informações sobre a estrutura molecular. Para isso foi utilizado um analisador termogravimétrico TGA7 da Perkin-Elmer. Todas as amostras foram analisadas após liofilização. O aquecimento foi feito em uma razão de $10^{\circ} \mathrm{C} \cdot \mathrm{min}^{-1}$, em atmosfera dinâmica de nitrogênio na vazão de $25 \mathrm{ml} . \mathrm{min}^{-1}$. Os eventos térmicos foram registrados em função da composição, estrutura do material e de sua história térmica. Para isso foi utilizado um analisador térmico DSC 2920 TA Instruments. O aquecimento foi feito em uma razão de $10{ }^{\circ} \mathrm{C} \cdot \mathrm{min}^{-1}$ até temperatura de $450{ }^{\circ} \mathrm{C}$, em atmosfera inerte de nitrogênio, com vazão de $50 \mathrm{ml} \cdot \mathrm{min}^{-1}$.

\section{Análise mecânica por DMA}

No nosso caso, os ensaios mecânicos foram realizados com o objetivo de observar apenas a resistência mecânica das amostras, variando a força imposta à amostra no decorrer do tempo. Durante os ensaios, a temperatura permaneceu constante em $25^{\circ} \mathrm{C}$. Cada amostra, depois de ter sua dimensão medida, foi colocada em um dispositivo na forma de garras. As medidas ocorreram em função da deformação observada a partir da compressão das amostras. A rampa de força aplicada durante os ensaios foi de $0,01 \mathrm{~N} \cdot \mathrm{min}^{-1}$. As análises foram realizadas com o uso do equipamento TA Instruments Dynamic Mechanical Analyser (DMA) 2980 no modo força controlada.

\section{Avaliação da resistência química}

A resistência química ao ácido $\mathrm{HCl}$ foi realizada utilizando o mesmo protocolo de determinação do grau de desacetilação da quitosana ${ }^{[18]}$. As microesferas individualmente são deixadas em repouso durante $24 \mathrm{hs}$ em soluções de $\mathrm{HCl}$ 0,2 mol/L. Sua solubilidade foi avaliada visualmente durante esse período. Os ensaios foram realizados em triplicata.

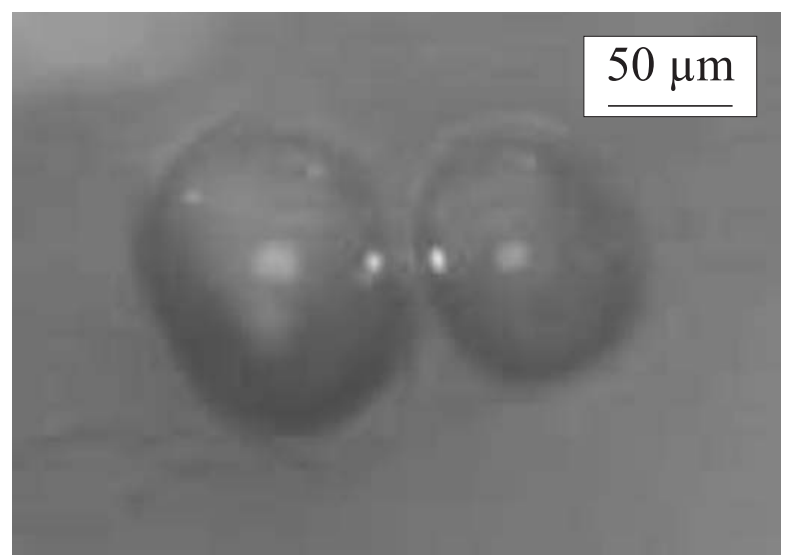

Figura 4. Fotomicrografia das microesferas de quitosana sem modificação.

\section{Resultados e Discussão}

Apesar da fotomicrografia mostrada na Figura 4 ser para a condição inicial (a), as demais condições (b), (c) e (d) apresentaram resultados de esfericidade bastante similares à natural independente da modificação realizada.

A análise de distribuição de tamanho das microesferas da Figura 5 mostrou um diâmetro médio em torno de $140 \mu \mathrm{m}$. A análise mostrou um desvio em relação à média de 11,9 mm conforme os resultados da Tabela-1.

A Tabela 2 apresenta valores do percentual de grupos amino para as amostras (a), (b), (c) e (d) obtidos pelo ensaio de titulação potenciométrica. A amostra reticulada com glutaraldeído não apresentou uma quantidade de grupos

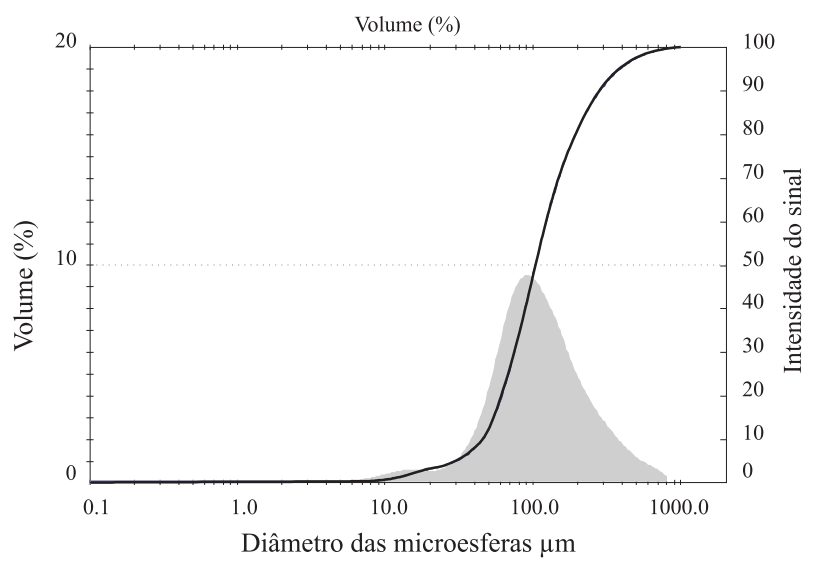

Figura 5. Distribuição de diâmetros das microesferas (naturais) obtida a partir das condições $2,5 \mathrm{kgf} . \mathrm{cm}^{-2}$ para pressão e $9,0 \mathrm{ml} \cdot \mathrm{min}^{-1}$ para vazão mássica .

Tabela-1. Reprodutibilidade dos ensaios de distribuição de tamanho das microesferas feitos na condição de $9,0 \mathrm{ml} \cdot \mathrm{min}^{-1}$ de vazão mássica e 2,5 kgf.cm ${ }^{-2}$ de pressão de $\mathrm{N}_{2}$.

\begin{tabular}{cc}
\hline Ensaio & $\begin{array}{c}\text { Diâmetro médio } \\
(\boldsymbol{\mu m})\end{array}$ \\
\hline 1 & 140 \\
2 & 129 \\
3 & 151 \\
\hline
\end{tabular}


Tabela-2. Percentual de grupos amino protonáveis das amostras, natural (a), reticulada com glutaraldeído (b), reticulada com epicloridrina (c) e acetilada (d).

$\begin{array}{cc}\mathrm{a} & 82,5 \\ \mathrm{~b} & \mathrm{nd} \\ \mathrm{c} & 68,7 \\ \mathrm{~d} & 70\end{array}$

nd $=$ sem valores nessa condição

amino protonáveis expressiva. Observou-se somente uma inflexão na curva de titulação potenciométrica, referente ao consumo de $\mathrm{NaOH}$ necessário para neutralizar o $\mathrm{HCl}$ adicionado. A amostra reticulada com epicloridrina apresentou um percentual de grupos amino próximo ao valor encontrado para a quitosana natural, indicando que esta reação deva atuar prioritariamente em outros grupos funcionais da quitosana além dos grupos amino. A amostra acetilada apresentou um percentual de grupos amino de $70 \%$.

A Figura 6 nos mostra os espectros FTIR-ATR para as amostras analisadas. Foi possível verificar a presença das seguintes bandas de absorção: $1060 \mathrm{~cm}^{-1}$ estiramento vibracional C-O do álcool primário; $1090 \mathrm{~cm}^{-1}$ estiramento vibracional do grupo éter; $1070-1100 \mathrm{~cm}^{-1}$ aminas alifáticas; $1654 \mathrm{~cm}^{-1}$ e $1380 \mathrm{~cm}^{-1}$ vibração de deformação de intensidade média N-H de amina primária e banda relativa à vibração de deformação angular simétrica de grupos metil do grupo acetamido; $1400 \mathrm{~cm}^{-1}$ grupos alquilas e carboxilatos $\mathrm{O}-\mathrm{C}=\mathrm{O}$; $1450 \mathrm{~cm}^{-1}$ vibração de deformação angular de grupos metilênicos $\mathrm{CH}_{2} ; 1550 \mathrm{~cm}^{-1}$ bandas de sobreposição de aminas $\mathrm{N}-\mathrm{H}$, amida $\mathrm{N}-\mathrm{C}=\mathrm{O}$ e carboxilato $\mathrm{O}=\mathrm{C}-\mathrm{O} ; 1725-1750 \mathrm{~cm}^{-1} \mathrm{e}$ $1230-1277 \mathrm{~cm}^{-1}$ grupos ésteres $\mathrm{C}=\mathrm{O}-\mathrm{O}$. Na amostra (b) pôdese observar que a intensidade da banda devido à amina alifática $\left(1100 \mathrm{~cm}^{-1}\right)$ diminuiu, denotando que estes grupos foram ligados as moléculas de glutaraldeído, formando uma nova estrutura denominada imina $(\mathrm{N}=\mathrm{C})$, conforme mostra a Figura 1-b. Este fato pôde ainda ser confirmado pelo aparecimento de um pico a $1655 \mathrm{~cm}^{-1}$ atribuído a ligação imina

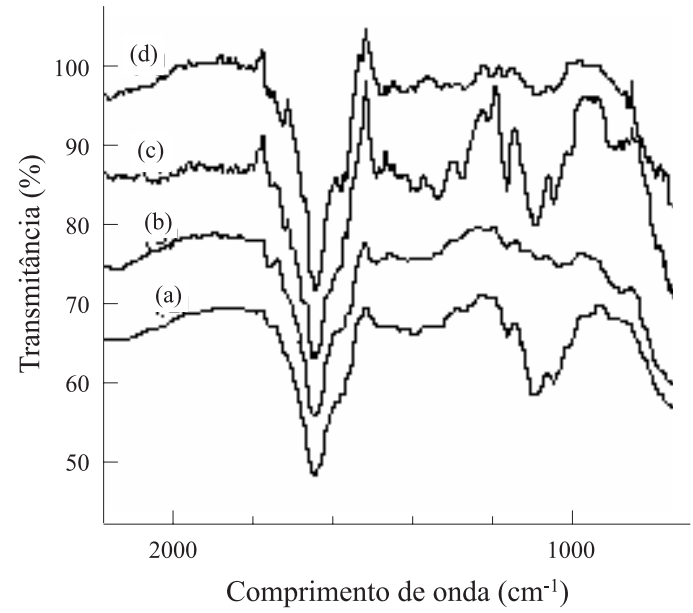

Figura 6. Espectros de FTIR-ATR para as microesferas natural (a), reticuladas com glutaraldeído (b), reticuladas com epicloridrina (c) e acetiladas (d)
$\mathrm{N}=\mathrm{C}^{[12-19]}$ e outro pico a $1562 \mathrm{~cm}^{-1}$ associado à ligação etilênica $\mathrm{C}=\mathrm{C}$. Pôde-se observar o aparecimento de bandas características entre $1700-1750 \mathrm{~cm}^{-1}$ relacionadas aos grupos aldeídicos livres, os quais não reagiram com o polímero. Especialmente em reticulações extremas, como é o nosso caso, validado pelo resultado da titulação potenciométrica, as moléculas bifuncionais do glutaraldeído não têm necessariamente ambos os grupos aldeídicos ligados à quitosana e funções aldeídicas podem estar disponíveis na matriz final reticulada.

$\mathrm{Na}$ amostra (c) observou-se um aumento na intensidade entre 1000-1300 cm-1, indicando a formação da ligação C-O, característico do processo de reticulação com epicloridrina, conforme mostra a Figura 1-c ${ }^{[20]}$. Na amostra (d) pôde-se observar que a intensidade da banda devido à amina alifática $\left(1100 \mathrm{~cm}^{-1}\right)$ diminuiu, indicando a acetilação destes grupos pelo anidrido acético. Estes resultados concordam com aqueles apresentados pela titulação potenciométrica onde se observou que parte dos grupos amino foram acetilados.

A Figura 7 mostra os resultados obtidos das análises termogravimétricas para as microesferas. Observa-se que a degradação das amostras ocorre em dois estágios distintos. O primeiro referente à perda de água residual das amostras, $\mathrm{e}$ o segundo, referente à degradação das amostras propriamente dita. No primeiro estágio, é possível verificar que a amostra reticulada com glutaraldeído (b) retém menos água e com isso volatiliza mais facilmente. Esse comportamento sugere que os grupos amino, de caráter hidrofílico, encontram-se ligados aos grupos aldeídicos ${ }^{[12,14,19,20]}$, concordando com os resultados apresentados pela titulação potenciométrica e pelo FTIR-ATR. Como conseqüência observou-se uma queda em sua resistência térmica. Já as temperaturas de degradação das amostras (a), (c) e (d) ficaram muito próximas, em torno de $300^{\circ} \mathrm{C}$. O fluxo de massa perdido, associado à perda de água, para as amostras (a), (c) e (d) apresentaram comportamentos similares. Podemos inferir com isso que a reticulação com epicloridrina influenciou apenas parcialmente o caráter hidrofílico da amostra (a), com o bloqueio preferencial aos grupos hidroxílicos, e não aos grupos amino. $\mathrm{O}$ aumento das unidades monoméricas acetiladas na amostra (d) não alterou

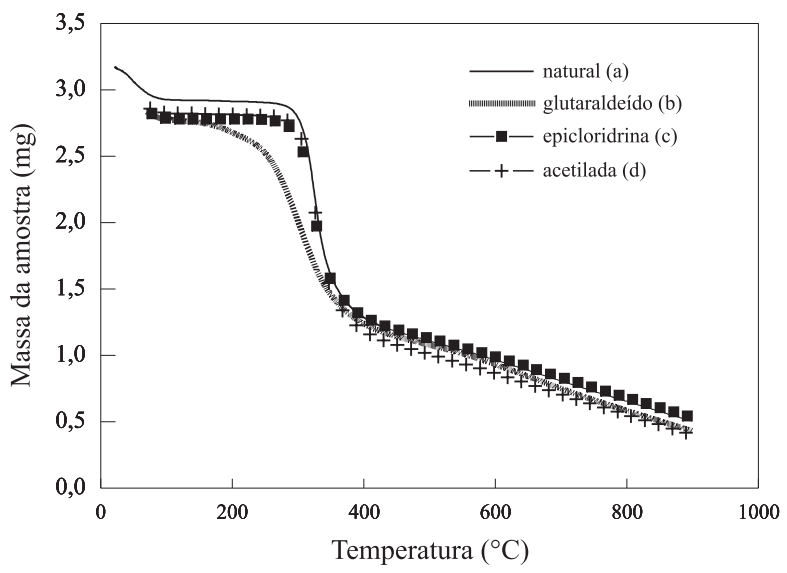

Figura 7. Análise termogravimétrica das microesferas de quitosana (a) natural, (b) reticulada com glutaraldeído, (c) reticulada com epicloridrina e (d) acetilada. 


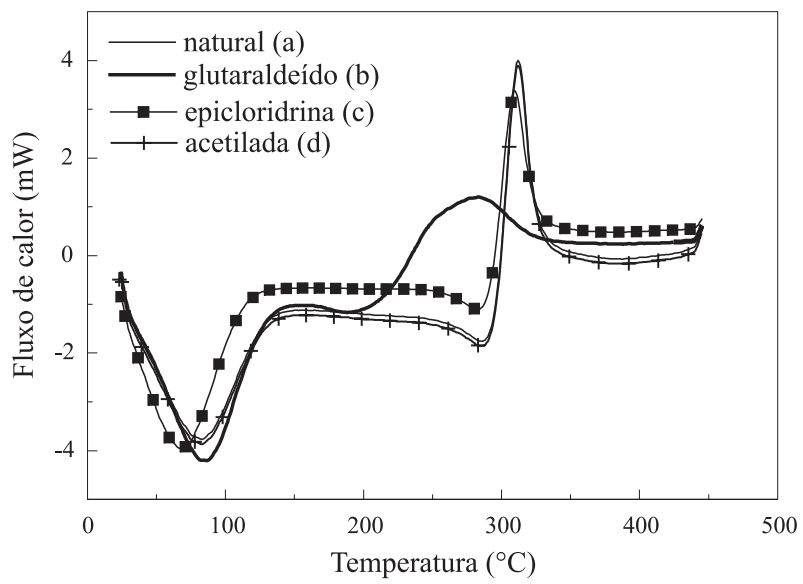

Figura 8. Perfil térmico obtido por DSC para as microesferas de quitosana (a) natural, (b) reticulada com glutaraldeído, (c) reticulada com epicloridrina e (d) acetilada.

de forma importante o caráter hidrofílico, apresentando resultados próximos aos encontrados nas amostras (a) e (c).

A Figura 8 mostra os resultados obtidos pelas análises de calorimetria exploratória diferencial para as microesferas. Observa-se em todas as amostras um pico endotérmico relacionado à evaporação de água e um pico exotérmico relacionado à capacidade de retenção de água. O comportamento é similar para as amostras (a), (c) e (d). Já para a amostra (b) reticulada com glutaraldeído é possível verificar que o pico exotérmico é menos intenso quando comparado às demais amostras. Essas observações confirmam os resultados encontrados nas análises termogravimétricas, relacionando as alterações promovidas pela reticulação com glutaraldeído com a baixa capacidade de retenção de água pelas cadeias hidrofóbicas.

A Figura 9 mostra os resultados obtidos pelas análises mecânicas para as microesferas. Foi possível observar comportamento similar nas curvas (a), (c) e (d) com relação à estabilidade das amostras após aplicação de força de compressão em torno de $0,5 \mathrm{~N}$. Mas todas as amostras, após as respectivas modificações químicas, apresentaram perda de resistência mecânica quando comparados à amostra (a). A amostra (c) apresentou inicialmente maior deformação na mesma tensão imposta quan-

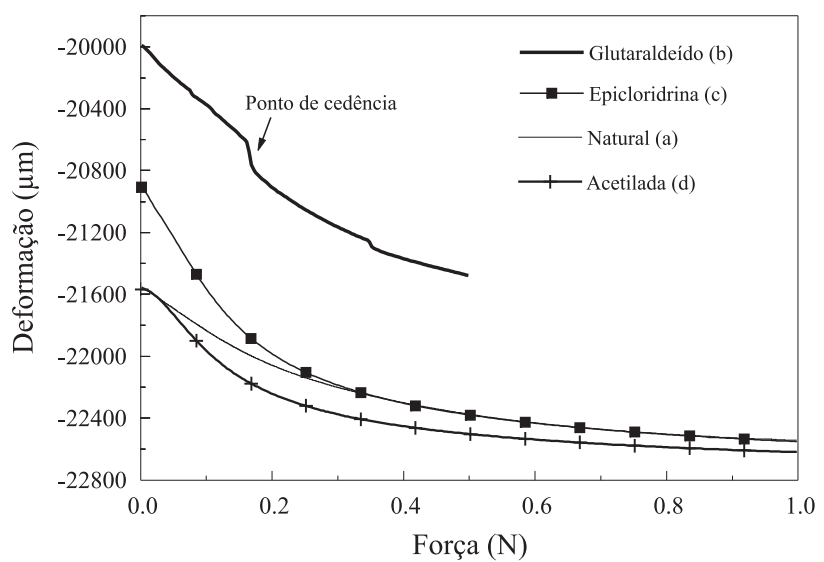

Figura 9. Perfil obtido por DMA para as microesferas de quitosana (a) natural, (b) reticulada com glutaraldeído, (c) reticulada com epicloridrina e (d) acetilada.
Tabela 3. Valores de solubilização das amostras em solução aquosa de $\mathrm{HCl}$ $0,2 \mathrm{~mol} / \mathrm{L}$ pelo tempo máximo de $48 \mathrm{hs}$.

\begin{tabular}{ccc}
\hline Amostras & Solúveis & Insolúveis \\
\hline a & 10 & nd \\
b & nd & 48 \\
c & nd & 48 \\
d & 12 & nd \\
\hline
\end{tabular}

nd= sem valores nessa condição

do comparada às demais, mas com flexibilidade suficiente para alcançar a estabilização sem ruptura do material. A amostra (d) teve comportamento próximo a amostra (a). Já a amostra (b), comparativamente, apresentou deformação acentuada em todo o ensaio (sinal de um material mais rígido) com a ruptura da amostra caracterizado na curva, pelo ponto de cedência. Esse fenômeno ocorreu após a aplicação de uma força equivalente a $0,15 \mathrm{~N}$. Diferentemente das demais amostras, a amostra (b) apresentou esfarelamento após o ensaio (já observado durante o manuseio), mostrando, nesse caso, que a reticulação com glutaraldeído alterou mais intensamente o empacotamento das cadeias macromoleculares e seu relaxamento após ser submetido a tensões diminuindo a flexibilidade final da amostra.

Nos ensaios de solubilidade ao ácido clorídrico, conforme Tabela 3, podê-se observar que as amostras (a) e (d) foram totalmente solubilizadas após 10 e 12 horas de contato com a solução ácida, respectivamente. Esses tempos de solubilização próximos indicam disponibilidade similar de grupos amino na estrutura macromolecular dessas amostras. As amostras (b) e (c) não apresentaram nenhum traço de solubilização após 48 horas de observação visual, mostrando que as modificações promovidas nesses dois casos resultaram no bloqueio dos grupos amino em grau suficiente para elevar sua resistência química nas condições citadas.

\section{Conclusões}

O processo de atomização e coagulação mostrou-se: 1eficaz para a obtenção de microesferas de quitosana; 2reprodutível; 3- simples e 4- possível de se realizar em maior escala.

Esforços concentrados na otimização dos parâmetros operacionais (pressão; vazão mássica e altura entre o bico de atomização e a solução coagulante) podem vir a gerar microesferas com distribuição de tamanhos mais adequada a cada aplicação.

As análises térmicas mostraram que há diferença na perda de água e na temperatura de degradação entre as amostras naturais, reticuladas com epicloridrina, e acetiladas com relação às amostras reticuladas com glutaraldeído. O que nos leva a inferir que a alteração induzida pela reticulação com glutaraldeído afeta os grupos amino das cadeias poliméricas e por conseqüência a sua hidrofobicidade em maior intensidade.

As modificações químicas realizadas não contribuíram para aumentar a estabilidade mecânica das amostras analisadas em 
comparação com a amostra natural. Em especial as microesferas após reticulação com glutaraldeído tiveram sua estrutura comprometida quando aplicadas forças superiores a $0,15 \mathrm{~N}$.

As microesferas após as modificações químicas com epicloridrina e glutaraldeído tiveram um aumento acentuado de resistência química à solução aquosa de $\mathrm{HCl}$ quando comparadas as microesferas naturais. Já com as microesferas acetiladas, o valor de $12 \mathrm{~h}$, próximo das microesferas naturais (10h), mostra que o grau de desacetilação de $70 \%$ não foi suficiente para conferir a amostra (d) aumento significativo na resistência química à solução aquosa de $\mathrm{HCl}$.

\section{Agradecimentos}

Os autores agradecem o suporte financeiro da FAPESP e CNPq.

\section{Referências Bibliográficas}

1.Roberts, G. A. F.; "Chitin Chemistry", The Macmillian Press Ltd, London (1992).

2. Tangpasuthadol, V.; Pongchaisirikul, V. \& Hoven, V.P.Carbohydrate Research, 338, p.937 (2003).

3. Lee, S.T.; Mi, F.L.; Shen, Y.J. \& Shyu, S.S. - Polymer, 42, p.1879 (2001).

4. Huang, R.Y.M.; Moon, G.Y. \& Pal, R.- Journal of Membrane Science, 176, p.223 (2000).

5. Chirachanchai, S.; Lertworasirikul, A \&\& Tachaboonyakiat, W. - Carbohydrate Polymers, 46, p.19 (2001).

6. Muslim, T.; Morimoto, M.; Saimoto, H.; Okamoto, Y.; Minami, S.\& Shigemasa, Y. -Carbohydrate Polymers, 46, p.323 (2001).

7. Yamaguchi I.; Itoh S.; Suzuki M.; Osaka A. \& Tanaka J., Biomaterials, 24, p.3285 (2003).

8. Mi, F. M.; Shyu, S.S.; Chen, C.T. \& Schoung, J.Y.Biomaterials, 20, p.1603 (1999).
9. Mi, F.L., Wong, T.B., Shyu, S.S. \& Chang, S.F., - Journal of Applied Polymer Science, 71, p.747 (1999).

10. He, P., Davis, S.S. \& Illum, L., - International Journal of Pharmaceutics, 187, p.53 (1999).

11. Muzzarelli, R. A. A. "Chitin Handbook", Plenum, editors, Italy, (1977).

12. Monteiro Jr., O.A.C., Airoldi C., International Journal of Biological Macromololecules, 26, p.119 (1999)

13. Wei, Y. C.; Hudson, S. M.; Mayer, J. M. \& Kaplan, D. L. - Journal of Polymer Science, 30, p.2187 (1992).

14. Knaull Z.J., Hudson, S.M., Creber, A.M.K., Journal Polymer Science. - Part B: Polymer. Physical, 37(11), p.1079 (1999).

15. Hirano, S.; Ohe, Y. \& Ono, H. - Carbohydrate Researsh 47, p.315 (1976).

16. Arruda, E.J.\& Santana, C.C. “ Concentração e purificação de b-amilase de extrato de soja por adsorção em gel de afinidade quitosana-fenilboronato. "Tese de Doutorado, FEQ-Unicamp, Brasil, (1999).

17. Torres, M. A. \& Santana, C. C. "Propriedades viscosas e viscoelásticas de soluções e géis de quitosana", Dissertação de Mestrado, FEQ-Unicamp, Brasil, (2001).

18. L. Raymond, F.G. Morin \& R.H. Marchessault, Carbohydrate Researsh, 246, p.331 (1993).

19. Koyama, Y., Taniguchi, A., Huang, C.P., Blakenship, D.W., Journal of Applied Polymer Science, 31, p.1951 (1986).

20. Ngah, W.S.W., Endud, C.S., Mayanar, R., Reactive Functional Polymer, 50, p.181 (2002).

Enviado: 17/03/05

Reenviado: 25/07/05

Aprovado: 30/07/05 